\title{
Welsh Division Trainees Day
}

\author{
J. W. T. LOVETT, Collegiate Trainees Committee (CTC) Representative, Welsh Division
}

The first ever Welsh Division Trainees Day took place at Whitchurch Hospital, Cardiff on 13 May 1986. Although geographically one of the larger, Wales is numerically one of the smaller Divisions of the College, with only 33 Inceptors and 27 senior trainees (as at April 1986). Nevertheless the attendance was satisfactory for such an initial event with 34 trainees attending, of whom 13 came from peripheral hospitals. Unfortunately, no doubt because of the distances involved, there were no trainees from North Wales or Carmarthen.

The meeting was opened by Dr J. M. Cuthill (Consultant Psychiatrist, Parc Hospital, Bridgend, Regional Adviser) who chaired the morning session. The first speaker, Dr M. Harper (Senior Lecturer and Clinical Tutor, University Hospital of Wales) outlined the aims and objects of the Approval Exercise, and recounted from his experience as a Convener how an attempt was made to achieve these in practice. He described the problems of eliciting an accurate picture of a training scheme in a very short time, and of reconciling service and training needs. A lively discussion then centred on whether the visitors had an entirely inquisitorial role, being unwilling to accept a lack of criticism from trainees of their trainers. It was suggested that a training scheme in which the junior doctors were apparently wholly satisfied was not thereby necessarily wholly satisfactory.

Dr T. M. Hayes (Director and Dean of the Department of Postgraduate Studies, University Hospital of Wales) spoke next, with a wide-ranging and lucid talk on various topics of importance to psychiatric trainees. He discussed the essential elements of career planning, together with practical advice on how to draw up a curriculum vitae and then enhance one's chances of getting on the short list for an appointment. He guided his audience through the minefield of manpower acronyms, clarifying the work of JPAC and suggesting various implications for the future, including the rather refreshing idea that a bored 45 year-old consultant might enjoy the opportunity of a change of career. This naturally led to the audience discussing with some spirit the acceptability of a sub-consultant grade. Dr Hayes ended his talk with a review of future developments in postgraduate medical education, with particular relevance to audioconferencing techniques which had been pioneered in Wales for MRCP and MRCOG courses and are presently being considered for MRCPsych courses.

The morning session was closed by Dr Ann Gath (Consultant Child Psychiatrist, The Drummond Clinic, Bury St Edmunds), who gave a wide ranging and stimulating talk on the interface between child psychiatry and the psychiatry of mental handicap, surveying both the theoretical and the practical aspects of the subject. Her plea for mental handicap specialists to come from a variety of different specialities and her contention that "in mental handicap we see human nature at its greatest and its saddest" provoked a lively discussion on the possible reasons for the split between mental handicap and child psychiatry, and the difficulties involved in combining them in a satisfactory Senior Registrar training.

After lunch we divided into two workshops, one concerned with the MRCPsych examination chaired by $\mathrm{Dr}$ V. A. Cowie (Senior Lecturer, University Hospital of Wales) and one, interestingly nearly as large, concerned with appointment interview techniques, chaired by $\operatorname{Dr} M$. Harper. Both workshops involved role play, with a 'mock' clinical presentation having been prepared for the examination group, who also underwent 'mock' orals, and 'mock' interviews based upon rapidly completed application forms taking place in the other group.

The afternoon ended with a plenary session in which the CTC representatives, (Dr D. Greedharry, Dr S. Watkins and $\mathrm{Dr} J$. Lovett) answered questions about the structure and role of the CTC, and sought to elicit what issues were of especial interest to trainees in Wales. It became apparent that there were considerable differences in the degree of political organisation between groups of trainees in the Principality, and this led to the airing of a variety of local grievances. Anxiety was expressed over the position of overseas doctors with limited registration, the supremacy in some training schemes of service over training needs, and the existence of undue restrictions upon study leave.

Throughout the meeting literature about the College, and about the new exam format, was available. The pamphiets about the latter disappeared very rapidly.

It is apparent that both by intention and by event this Welsh Trainees Day reflected many of the concerns of the present psychiatric trainee. There appears to be increasing tension between training and service needs. This must be partly due to the success of the College in encouraging an awareness of training needs, but is probably also due to the rapidly changing manpower situation with the development of a severe 'bottleneck' at the Registrar/Senior Registrar level. The psychiatric trainee is increasingly aware of the importance of maximising his chances of promotion by good training, and, as noted in a previous Trainees Day elsewhere, it is the overseas graduate in a peripheral hospital who perceives himself at most risk of losing out on this training. ${ }^{1}$ The suggested responses to these problems included a greater flexibility of career structure, with the establishment of a subconsultant grade, and the dissemination of teaching from 'centres of excellence' by audio conferencing techniques. The former remains controversial, the latter is still in a developmental stage in psychiatric training, although a reasonably successful experiment was reported from Sheffield University last year. ${ }^{2}$

One anxiety remains perennial-the Membership 
examination. However, here concern has been heightened by uncertainty over what is the new exam format and how it will work, and by changes in the clinical examination, with the introduction of mentally handicapped patients and a new approach to the oral examination.

During the day trainees were asked to complete a questionnaire. The larger part of this related to manpower matters, training audit and CTC issues. This has also been sent to all trainees who were not able to attend and it is hoped that the results will be reported in due course. The remainder of the questionnaire was an audit of the day's proceedings. This was satisfactory with $\mathbf{8 8} \%$ of trainees thinking there was enough academic content to the day's programme, $76 \%$ happy with the exam content, and $82 \%$ satisfied with the time spent on practical training issues. The workshops were considered helpful by $82 \%$, and $100 \%$ rated the speakers as good rather than bad or indifferent. I would like to thank all who helped to make this first Welsh Division Trainees Day a success.

Repreances

${ }^{1}$ Crawford, D., Davidson, I. A. \& Simpson, N. (1984) North West Division Trainees Day. Bulletin of the Royal College of Psychiatrists, 8, 201.

${ }^{2}$ SEAGER, C. P. (1985) The use of the telephone in continuing psychiatric education-sucesses and failures. Bulletin of the Royal College of Psychiatrists 9, 200-201.

\title{
Inaugural Meeting of the Scottish Division's Management Group
}

\author{
DAvid TaIt, Consultant Psychiatrist, Murray Royal Hospital, Perth
}

The Scottish Division has formed a group with a special interest in management, which held its first meeting in Murray Royal Hospital, Perth on 7 November 1986. Over 60 delegates attended, representing three quarters of all Scottish mental illness and mental handicap hospitals, the Mental Welfare Commission and the Scottish Home and Health Department. Local interest was also high, with Dr Ronnie Graham, General Manager of Tayside Health Board and three of his medical colleagues from the Board present, as were heads of clinical departments from Murray Royal.

Dr John Scott, Physician Superintendent at Murray Royal, took the Chair, and Dr David Tait, also from Perth, presented the first paper. He summarised the position of the younger consultant with a developing interest in management, in terms of Griffiths' original ideas and their application in Scotland, opportunities for formal training and practical experience, and the nature of general managers and their work as described in the business world.

The second paper from Judith Brearley, a social worker and a member of the Scottish Institute of Human Relations, explored the changes which are part of management from a psychodynamic viewpoint. Drawing on her experience in organisational consultancy she used the model of crisis, with its dual components of danger and opportunity, to identify the challenges to be met.

After lunch Raymond Miquel, recently appointed Chairman of Belhaven, past Chairman of Bell's and also visiting Professor of Business Development in Glasgow University, spoke of management techniques in business. He addressed a number of themes including the importance of the size of the unit to be managed, the need for simplicity of organisation, for clear lines of communication and for motivation of staff.

Readers of the Bulletin will have relished Dr James Affleck's 'Perspective' in the September 1986 issue. He presented the day's final paper, reflecting on his own career and the changes in the management of psychiatric services wrought by successive NHS reorganisations. These have ultimately been to the detriment of patient needs and Dr Affleck made a call for "management by clinical objective". Such management calls for recognition of the sapiential authority of the psychiatrist and in turn his willingness and ability to co-ordinate a comprehensive service crossing hospital/community and organisational boundaries.

Those clinicians who attended decided that a Management Group of the Scottish Division should be inaugurated, and elected Dr Tait as Chairman, and Dr Alasdair McKechnie, Physician Superintendent of Bangour Village Hospital, Broxburn, West Lothian, as Secretary. The next meeting will be held in Bangour on 23 January 1987 and will be concerned with local management issues and with how best to continue clinical input into management of psychiatric services as Unit General Managers in Scotland take up post. Any Scottish psychiatrist (including trainees) wishing to join the Management Group should write to the Secretary. 